\title{
Incarcerated Hiatal Hernia After Robot-Assisted Esophagectomy: Transhiatal Versus Thoracoscopic Approach
}

\author{
Daniel Dunn • Nilanjana Banerji
}

Published online: 29 December 2011

(C) Springer Science+Business Media, LLC 2011

To the Editor,

We are grateful to Dr. Boone and colleagues for their insightful comments regarding our report on the incidence of incarcerated hiatus hernia after robotic-assisted transhiatal esophagectomy [1]. We agree with Dr. Boone and colleagues that a complication of an incarcerated hiatal hernia should not be induced by a transthoracic approach, as the integrity of the hiatus is maintained by this surgical technique. We wish to mention that our purpose in performing total esophagectomy via robotic transhiatal approach is to eliminate thoracoscopy or thoracotomy either by minimally invasive techniques, such as that utilized by Dr. Boone and coworkers, or as defined and reported by Luketich et al. [2]. Similar to the robotic thoracoscopic and minimally invasive thoracoscopic-laparoscopic approaches, the robotic-assisted transhiatal approach has minimal blood loss, NCCN guideline-recommended lymph node retrieval, acceptable operating times, and low mortality rates. A robotic-assisted transhiatal approach minimizes patient pain and discomfort compared with a thoracic approach, as well as reduces the risks of pulmonary complications that necessarily arise from entering the chest cavity.

Relatively few reports of a transhiatal robotic approach for esophagectomy exist in the published literature [3-5]. Since our group is one of the few adopting this approach, the primary intent of the report was to share lessons learned from our initial experience with other surgeons who might wish to pursue this technique. We reiterate that in

\section{Dunn $(\bowtie)$}

Esophageal and Gastric Cancer Program, Virginia Piper Cancer Institute, Minneapolis, USA

e-mail: docdunn3@comcast.net

N. Banerji

Applied Research, Allina Hospitals and Clinics, Minneapolis, USA individuals with an already widened hiatus, a robotic transhiatal procedure poses a risk of stretching the hiatus to a point where a paragastric hiatus hernia may result.

As mentioned in our publication, the technique that we suggest is a lateral repair approach by use of an onlay biologic mesh over the lateral part of the hiatus to decrease the size of the hiatus, thereby not impinging on the stomach and possibly compromising the blood supply to the gastric pull-up. Additionally, suturing the graft to the gastric pull-up prevents herniation of small bowel or colon through the hiatus.

In closing, we acknowledge the fact that a thoracoscopic esophagectomy would certainly minimize the chances of an incarcerated hiatal hernia. However, since our implementation of the preventive technique (within selected patients) described in our report, we have not encountered any complications of incarcerated hiatus hernia within our practice.

\section{References}

1. Sutherland J, Banerji N, Morphew J, Johnson E, Dunn D (2011) Postoperative incidence of incarcerated hiatal hernia and its prevention after robotic transhiatal esophagectomy. Surg Endosc 25:1526-1530

2. Luketich JD, Alvelo-Rivera M, Buenaventura PO, Christie NA, McCaughan JS, Litle VR, Schauer PR, Close JM, Fernando HC (2003) Minimally invasive esophagectomy: outcomes in 222 patients. Ann Surg 238:486-494

3. Galvani CA, Gorodner MV, Moser F, Jacobsen G, Chretien C, Espat NJ, Donahue P, Horgan S (2008) Robotically assisted laparoscopic transhiatal esophagectomy. Surg Endosc 22:188-195

4. Gutt CN, Bintintan VV, Köninger J, Müller-Stich BP, Reiter M, Büchler MW (2006) Robotic-assisted transhiatal esophagectomy. Langenbecks Arch Surg 391:428-434

5. Horgan S, Berger RA, Elli EF, Espat NJ (2003) Robotic-assisted minimally invasive transhiatal esophagectomy. Am Surg 69:624-626 